\title{
Produção nos PPGs sobre ação clínica numa perspectiva fenomenológica existencial: análise compreensiva
}

\section{Production in PPGs on clinical action in existential phenomeno- logical perspective: comprehensive analysis}

DOI: http://dx.doi.org/10.12957/ek.2014.13763

Prof $^{a}$ Dnda $^{a}$ Suely Emilia de Barros Santos suely.emilia@upe.br UPE
Prof ${ }^{\mathrm{a}} \mathrm{Dr}^{\mathrm{a}}$ Carmem Lúcia

Brito Tavares Barreto

carmemluciabarreto

(a) hotmail.com

UNICAP
Prof $^{\mathrm{a}} \operatorname{Dr}^{\mathrm{a}}$ Henriette Tognetti Penha Morato

hmorato@usp.br USP

Este artigo visa apresentar uma análise compreensiva, orientada pela hermenêutica filosófica de Gadamer, dos resultados encontrados na pesquisa "O Estado da Arte: prática psicológica clínica na perspectiva fenomenológica existencial". A referida pesquisa teve como objetivo fazer um levantamento da produção de conhecimentos dos Programas de Pós-Graduação de Instituições de Ensino Superior, acerca da ação clínica de psicólogos e da prática psicológica numa perspectiva fenomenológica existencial, ao modo de Heidegger. Considerando o propósito do artigo, ele será dividido em dois momentos. Primeiro, serão apresentados e discutidos os resultados encontrados na pesquisa-guia. Segundo, será realizada uma análise compreensiva dos resultados obtidos, via hermenêutica filosófica de Gadamer, dialogando com Martin Heidegger, Walter Benjamin e Michel Serres. Refletindo sobre estes resultados, consideramos a insuficiência de pesquisas com essa proposta, bem como a importância dos pesquisadores deixarem explícita sua perspectiva epistemológica e metodológica a fim de contribuir para a produção de conhecimento na referida área.

PALAVRAS-CHAVE ação clínica. prática psicológica. fenomenologia.

existencial.análise compreensiva. 
This work aims to present a comprehensive analysis, guided by Gadamer's philosophical hermeneutics, of the results found in the study "The State of Art: clinical psychological practice in the existential phenomenological perspective". This research aimed to survey the production of knowledge from Post-Graduate Program of Universities, about the clinical action of psychologists and psychological practice in an existential phenomenological perspective, according to Heidegger's. Considering the purpose of the study, this will be divided into two moments. In the first moment the results from the guide research will be presented and discussed. In the second moment a comprehensive analysis of the obtained results will be held via Gadamer's philosophical hermeneutics, dialoging with Martin Heidegger, Walter Benjamin and Michel Serres. Reflecting on these results, we consider the insufficiency of research in this area, as well as the importance of the researchers explicit their epistemological and methodological perspective, in order to contribute to knowledge production in this field.

KEYWORDS

clinical action. psychological practice. existential phenomenology. comprehensive analysis. 


\section{Introdução}

A perspectiva fenomenológica tem despertado o interesse de profissionais da área de Psicologia Clínica que atuam tanto na clínica psicoterápica como em outras modalidades da prática psicológica, desenvolvidas em serviços privados e públicos. É também evidente o crescente número de pesquisas realizadas nos Programas de Pós-Graduação (PPGs), privilegiando esta perspectiva. Tal quadro norteou o interesse para desenvolver uma pesquisa realizada no Programa de Iniciação Científica da UPE/2013 sobre "O estado da arte: prática psicológica clínica na perspectiva fenomenológica existencial”, com o objetivo de fazer um levantamento sobre a produção de conhecimento desenvolvida nas pesquisas realizadas nos PPGs acerca da ação clínica de psicólogos e da prática psicológica numa perspectiva fenomenológica existencial.

De posse dos resultados, já divulgados nos anais do Encontro de Pós-Graduação, Pesquisa e Extensão - Seminário de Inovação Tecnológica e Seminário de Extensão da UPE em 2013, perguntamo-nos que possibilidades poderiam ser abertas a partir dos dados encontrados. Uma delas foi desenvolver uma análise compreensiva dos referidos resultados pela via da Hermenêutica Filosófica de Gadamer (2008; 2010), buscando estabelecer um diálogo possível entre o pensamento desenvolvido por Heidegger em "Serenidade" (1959), com as perspectivas de Walter Benjamin (1994) e Michel Serres (1993). Caminhando em tal direção, passaremos a desenvolver algumas considerações.

Em um primeiro momento, faremos uma breve apresentação da pesquisa realizada com uma breve discussão qualitativa dos resultados obtidos sobre a produção científica dos Programas de Pós-Graduação em relação à Ação Clínica/Prática Psicológica na Perspectiva Fenomenológica Existencial. Tal etapa é importante para encaminhar a proposta do presente artigo, desenvolvida em um segundo momento - apresentar uma análise compreensiva dos resultados encontrados pela via Hermenêutica Filosófica de Gadamer, fazendo uma torção no modo explicativo, ou mesmo descritivo, de contar sobre um mapeamento bibliográfico, possibilitando a explicitação da rede de sentido tecida por uma análise compreensiva hermenêutica.

\section{Situando a Pesquisa-Guia e a relevância do "Estado da Arte"}

A pesquisa " $\mathrm{O}$ estado da arte: prática psicológica clínica na perspectiva fenomenológica existencial" passa a ser considerada como "Pesquisa-Guia" já que vai fornecer subsídios para a análise compreensiva/hermenêutica que será 
desenvolvida como proposta do estudo em pauta.

O percurso investigativo revelou dados importantes que podem ser tomados como fonte de referência para diversos estudos sobre a aludida temática. Colocou em evidência um conjunto de dados sobre os estudos e pesquisas produzidos, nos últimos 13 anos, no Brasil, sobre a produção de conhecimentos nos Programas de Pós-Graduação acerca da Ação Clínica e Prática Psicológica na Perspectiva Fenomenológica Existencial.

De acordo com Ferreira (2002), nesses últimos quinze anos têm sido produzidas pesquisas conhecidas como "Estado da Arte". Essas pesquisas são reconhecidas pelo seu caráter bibliográfico, possibilitando que o pesquisador se coloque frente ao desafio de realizar um mapeamento de produções acadêmicas e fazer uma discussão sobre o tema abordado.

O que levou a escolha de tal metodologia foi o pressuposto de que não havia um conhecimento relevante acerca do que já tinha sido construído sobre a temática a ser investigada neste estudo: a ação clínica numa perspectiva fenomenológica existencial.

Para atingir tal proposta, foi feito um levantamento da produção de conhecimentos nos programas de pós-graduação sobre ação clínica numa perspectiva fenomenológica existencial, no período de 2000 até setembro de 2013, partindo de descritores que pudessem ofertar informações sobre a perspectiva epistemológica às modalidades de intervenção e às Instituições de Ensino Superior em que se desenvolveram. Debruçarmo-nos sobre esse mapeamento revela que intentamos abrir outras possibilidades de investigação para ação clínica de psicólogos, ainda pouco debatidas pelas pesquisas de mestrado e doutorado. Como bem afirma Ferreira (2002), os pesquisadores que fazem essa opção metodológica estão apoiados e movidos a se debruçarem sobre estudos já realizados, divulgá-los para a sociedade e depois construir o que ainda não foi produzido.

A partir desta exposição, reportamo-nos a Sposito (2009, p.11): "A confiabilidade de um levantamento que pretende caracterizar-se como Estado da Arte depende, em grande parte, do claro recorte do universo a ser investigado, das fontes disponíveis e do seu tratamento". Assim, passamos a apresentar o recorte da investigação realizada: o período, como já apontado acima, foi do ano de 2000 até 2013. Embora tenham aparecido na Plataforma CAPES trabalhos em anos anteriores a 2000, a produção foi muito pequena e os trabalhos produzidos, na maioria, eram em PPGs de áreas diferentes da Psicologia, com enfoques que não se apresentavam como objetivo da pesquisa, por isso, a escolha por este período. O recorte para o levantamento bibliográfico foi a produção discente 
da Pós-Graduação (dissertações e teses), das Instituições de Ensino Superior das regiões Nordeste e Sudeste do Brasil, pois, no primeiro momento da pesquisa, o levantamento apontou que os pesquisadores da temática em foco se concentravam nessas regiões.

A fonte de informação foram os trabalhos presentes no banco de dados da Coordenação de Aperfeiçoamento de Pessoal de Nível Superior - CAPES e da Biblioteca Digital Brasileira de Teses e Dissertações BDTD, a partir de três indicadores: título, palavras-chave e resumos, visando a circunscrever, com maior segurança, a proposta do estudo.

Logo foi possível perceber: a) que os trabalhos encontrados na plataforma da CAPES iam até o ano de 2011; b) que muitos dos trabalhos se repetiam nas duas plataformas; c) que era possível olhar para os trabalhos dos anos de 2012 e 2013 a partir da BDTD. Sem dúvida, essa primeira constatação nos pôs no lugar de saber-nos participantes de uma rede (in)acabada, pois produções se entrecruzam e essas plataformas são alimentadas com frequência, dando a nítida compreensão de que uma rede de conhecimentos sobre determinada temática estará em constante transformação.

Nas duas fontes de investigação a pesquisa considerou os seguintes descritores: Prática Psicológica e Fenomenologia, Prática Psicológica e Fenomenologia Existencial, Ação Clínica e Fenomenologia e Ação Clínica e Fenomenologia Existencial. Os descritores foram escolhidos considerando o objetivo da pesquisa e levando em consideração uma primeira leitura dos resumos que já apontava para certa dispersão entre os indicadores com relação às intervenções realizadas, como também já indicava para uma junção de perspectivas epistemológicas, sem a necessária contextualização e justificativa.

\section{Apresentação e discussão dos resultados encontrados na Pesquisa-Guia}

Destacamos que este item tem o propósito de apresentar e discutir os resultados encontrados na pesquisa-guia. Desse modo, deixamos explícito que este momento representa uma primeira leitura dos dados encontrados que serão, posteriormente, interpretados via hermenêutica filosófica de Gadamer - objetivo do presente estudo. 
Iniciando a apresentação dos resultados, constatamos que, nos dois bancos de dados, não havia uma diferenciação entre ação clínica e prática psicológica nos trabalhos encontrados. Tais descritores eram apresentados sem distinção, vinculados à fenomenologia ou à fenomenologia existencial. Para efeito do levantamento do estado da arte, passamos a considerar os respectivos descritores conjuntamente, já que não era objetivo, naquele momento do estudo, fazer a distinção ou caracterização das denominações utilizadas para indicar a intervenção do psicólogo. Assim, na pesquisa-guia, foram encontradas 153 dissertações e 58 teses com os descritores Ação Clínica/Prática Psicológica e Fenomenologia e 47 dissertações e 21 teses, com os descritores Ação Clínica/ Prática Psicológica e Fenomenologia Existencial.

Tais dados, ao demonstrarem que não há distinção nos trabalhos pesquisados entre ação clínica e prática psicológica, levaram-nos a revisitar os resumos dos trabalhos na busca de alguma diferenciação, o que não ajudou a esclarecer tal distinção. Sendo assim, apesar de não ser objeto de estudo da presente pesquisa, passamos a tentar delinear uma possibilidade de distinção entre os termos, no intuito de contribuir com a análise compreensiva a ser desenvolvida. Com este propósito revisitamos os trabalhos analisados, o que nos permite indicar que a ação clínica, mais indicada por autores que se referem a uma perspectiva fenomenológica existencial, se mostra como uma atitude de inclinar-se ao outro, de acompanhar o cliente numa '[...] 'ação preocupada', atenta ao modo como o cliente vive o seu cuidar, a sua existência, a sua história" (BARRETO, 2013, p.39, aspas da autora). Por outro lado, a indicação de prática psicológica não é utilizada, necessariamente, com referência a uma orientação determinada, vinculando-se, na maioria das vezes, a uma modalidade de intervenção clínica que acontece em um contexto específico, a partir de demandas que solicitam uma atenção psicológica. Diante de tal contexto, é possível apontar que a ação clínica, enquanto intervenção propriamente dita do psicólogo está presente nas diversas modalidades de prática psicológica, a saber: psicoterapia, plantão psicológico, psicodiagnóstico interventivo/colaborativo, entre outras. Como também podemos acrescentar que pode ser encaminhada por diversas orientações teóricas/epistemológicas e/ou escolas psicológicas.

Feitas tais explicitações, destacamos, primeiramente, que foram encontrados 68 trabalhos que apresentaram como descritores a ação clínica/prática psicológica e a perspectiva fenomenológica existencial, objeto de estudo da pesquisa-guia. Ao considerar os trabalhos desenvolvidos nas IES localizadas no Nordeste e Sudeste, escolha já justificada, passou-se a trabalhar com 50 dissertações e teses. No entanto, ao ler os resumos, considerando a questão 
epistemológica norteadora das pesquisas, observou-se que dos 50 trabalhos selecionados, apenas em 36 os pesquisadores apontavam uma orientação teórica e metodológica a partir da perspectiva fenomenológica existencial. Os demais afirmavam trabalhar com a Fenomenologia (02), Fenomenologia-Humanista (04) e orientação Fenomenológico-Existencial (08). Percebemos então, que tanto na plataforma da CAPES como na da BDTD, não há uma explicitação de qual aporte fenomenológico fundamenta a orientação seguida pelos pesquisadores.

$\mathrm{Na}$ tentativa de contribuir para compreender tais articulações, que representam olhares distintos com perspectivas metodológicas e epistemológicas definidas, consideramos importante começar recorrendo a Husserl e a sua proposta de uma Psicologia Fenomenológica. Tal proposta representa uma ruptura epistemológica com o pensamento vigente no final do século XIX, o qual se fundamentava na cisão sujeito-objeto, passando a apontar para a presença da intencionalidade da consciência em tal relação (CABRAL e MORATO, 2013). Esse olhar domina nos trabalhos que se apresentaram e foram nomeados como articulados a uma epistemologia fenomenológica.

A fenomenologia também está presente nos trabalhos que indicam seguir uma orientação da Psicologia Humanista. Nessa direção, articula-se com a proposta rogeriana, como indica Barreto (2006), como também com “o conceito de mundo vivido (Lebenswelt), tal como desenvolvida na fenomenologia mundana de Merleau-Ponty" (MOREIRA, 2009, p.16, grifo da autora). Tal junção permite falar numa orientação norteada pela fenomenologia-humanista.

Com relação ao referencial fenomenológico-existencial, segundo Feijoo (2002), este lança mão do método fenomenológico, o que mostra uma aproximação com o pensamento husserliano, mas visa, também, compreender o existir a partir da Analítica Existencial desenvolvida por Heidegger, como também em articulação com o existencialismo de Kierkegaard, Sartre entre outros.

No que se refere à Perspectiva Fenomenológica Existencial, ao modo de Heidegger, os trabalhos analisados apontam para uma "clínica psicológica aberta aos questionamentos dos diversos modos de ser do homem, compreendido como incompletude e indeterminação, como abertura e tarefa de ser" (BARRETO, 2013, p.38).

Com o intuito de contextualizar tais distinções, fizemos uma releitura dos resumos dos trabalhos, enfocando a compreensão dos autores em relação às perspectivas epistemológica e metodológica seguidas. Nos trabalhos identificados como tendo um referencial teórico-metodológico da Fenomenologia não foi possível identificar, nos resumos, os teóricos utilizados pelos autores. 
Com referência à fenomenologia humanista, ela vem acompanhada de uma intersecção com princípios que norteiam a Abordagem Centrada na Pessoa, tais como tendência atualizante, empatia, aceitação incondicional, congruência, dentre outros, bem como com a fenomenologia husserliana. Os autores presentes nos resumos foram Edmund Husserl, Carl Rogers e Merleau-Ponty. Os representantes da metodologia adotada nas pesquisas são: Hans-Georg Gadamer, Walter Benjamin, Amadeo Giorgi e Yolanda Forghieri. Vale destacar que Gadamer foi citado em apenas um dos trabalhos, havendo o predomínio de referência a Amadeo Giorgi e Yolanda Forghieri, apontando para uma forte influência das ideias husserlianas, uma vez que ambos caminham em um método fenomenológico, no qual podemos ver a imbricação de três aspectos fundamentais: a redução fenomenológica, a descrição e a busca das essências (FORGHIERI, 2002; GIORGI e SOUSA, 2010).

Em se tratando da denominação fenomenológico-existencial, essa se apresentou como uma abordagem e pensamento que apresentam uma perspectiva dialógica, lançando mão da contribuição de diferentes autores, tais como: Merleau-Ponty, Paulo Freire, Viktor Frankl, Wilhelm Reich, Alexander Lowen e Stanley Keleman. Em alusão à metodologia, apareceu apenas Yolanda Forghieri, mostrando uma forte influência do método fenomenológico husserliano.

O que dizer dos trabalhos que se apresentaram numa perspectiva fenomenológica existencial? Podemos apontar que assinalaram, na sua maioria, para um aporte da matriz fenomenológica existencial como possibilidade de repensar a ação clínica, mediante o diálogo com o pensamento de Heidegger. Nesses trabalhos, pudemos ver a marcação das contribuições de autores como Hannah Arent, Hans-Georg Gadamer, Medard Boss, Martin Heidegger, Eugene T. Gendlin, Michel Foucault, Jacob Levy Moreno, João Augusto Pompéia, Bilê Tati Sapienza e Gaston Bachelard. Quanto aos autores que guiaram a construção metodológica, encontramos: Walter Benjamin, Dulce Critelli, Hans-Georg Gadamer e Maria Luisa Schmidt. O trabalho interpretativo dos resultados funda-se na Hermenêutica Filosófica de Heidegger, voltando-se para uma compreensão interpretativa a qual se constrói considerando o Ser do homem como ser-no-mundo-com-outros, num encontro dialógico por meio da constante conversação (CRITELLI, 1996; GADAMER, 2008; 2010).

Partindo destes 36 trabalhos, nos quais os autores afirmavam, nos resumos, que caminhavam em direção a uma compreensão fenomenológica existencial, ao modo de Heidegger, a pesquisa-guia procurou identificar o modo como esses trabalhos estavam distribuídos nos cursos dos PPGs: 26 trabalhos foram realizados em mestrados e 10 trabalhos em doutorados. 
Essa produção de trabalhos nos PPGs reconhecidos epistemologicamente como sendo de uma perspectiva fenomenológica existencial, partindo de um diálogo com o pensamento de Heidegger, revela-nos que ainda é recente pesquisas sobre ação clínica e prática psicológica nessa perspectiva, apontando, de um lado, ser um campo novo, muitas vezes até desconhecido; e, de outro, mostra-se como um campo fértil para a produção acadêmica, o que reforça a relevância deste mapeamento e a importância de desenvolver pesquisas com a temática em foco: um campo teórico e metodológico ainda em construção a partir da prática em ação.

A partir dessa constatação, dirigiu-se o olhar para a distribuição das dissertações e teses desenvolvidas nas Instituições de Ensino Superior (IES) no Nordeste e Sudeste do Brasil, por ter sido nessas regiões a concentração de maior número de produções durante o primeiro levantamento realizado. Sete Instituições de Ensino Superior se fizeram presentes: Universidade Católica de Pernambuco - UNICAP, Universidade de São Paulo - USP, Universidade Federal Fluminense - UFF, Universidade Federal do Espírito Santo - UFES, Pontifícia Universidade Católica de São Paulo - PUC/SP, Universidade Federal do Rio Grande do Norte - UFRN, Universidade Federal do Rio de Janeiro - UFRJ.

Os resultados encontrados apontam para uma diferente concentração entre as pesquisas realizadas nos cursos de Mestrado e Doutorado, chamando atenção para uma produção mais significativa nos cursos de Mestrado do Nordeste em comparação com a produção dos cursos de Doutorado no Sudeste. Importa ressaltar que a produção no Nordeste concentra-se na UNICAP, que, até 2009, só contava com o curso de Mestrado, e a produção no Sudeste concentra-se na USP, que possui os cursos de Mestrado e Doutorado em Psicologia Escolar e do Desenvolvimento Humano, e que passaram a desenvolver pesquisas em fenomenologia existencial a partir da segunda metade da década de 90.

A discussão dos resultados relativos à concentração das produções em dois programas analisados baseou-se na consulta aos seus sites, na tentativa de encontrar possíveis diferenciais que permitissem oferecer elementos para discutir os resultados encontrados. Tal consulta permitiu apontar alguns itens que foram considerados como diferenciadores: o Programa de Pós-Graduação em Psicologia Clínica da Universidade Católica de Pernambuco (UNICAP) tem uma linha de pesquisa nomeada Práticas Psicológicas Clínicas em Instituições, e uma de suas sublinhas de pesquisa intitula-se "Práticas Psicológicas Clínicas na perspectiva Fenomenológica Existencial”, vinculada ao Laboratório de Psicologia Clínica Fenomenológica Existencial - LACLIFE, diferentemente das 
outras instituições que não têm uma linha de pesquisa específica em relação à prática psicológica e à fenomenologia existencial. Podemos, então, considerar que o crescimento de pesquisas na UNICAP se dá por ela vir construindo uma história em direção aos descritores aqui pesquisados: ação clínica e prática psicológica na perspectiva fenomenológica existencial, em diálogo com o pensamento de Heidegger.

O Departamento de Psicologia Escolar e do Desenvolvimento Humano do Instituto de Psicologia da USP, além de cursos de Mestrado e Doutorado, é formado pelo Laboratório de Estudos em Fenomenologia Existencial e Prática em Psicologia - LEFE - que desenvolve Projetos de Atenção Psicológica em Instituições, além de estágios e pesquisas acadêmicas com ênfase na perspectiva heideggeriana.

Podemos compreender que a clareza com que esses dois programas, com seus respectivos laboratórios, apresentam o olhar da perspectiva Fenomenológica Existencial, bem como o enfoque em trabalhos voltados para a ação clínica e a prática psicológica possibilita o crescimento de pesquisas sobre ação clínica e prática psicológica em tal perspectiva.

Seguindo, deparamo-nos com mais um resultado, agora apresentando as modalidades de Prática Psicológica presentes nos trabalhos pesquisados. Os dados apontavam para uma diversidade de modalidades de prática, bem como para diversos trabalhos que não enfocavam a questão da intervenção. Entretanto, não nos detivemos em diferenciá-las já que não era objeto de estudo da pesquisa realizada, ficando a sugestão aberta para outras pesquisas.

Diante de tais dados, podemos apontar que 13 (treze) dos trabalhos analisados indicaram uma vinculação com uma determinada modalidade de prática psicológica, enquanto que os demais trabalhos, apesar de enfocarem a temática em discussão, não se referem a uma modalidade de prática psicológica, quando discutem sobre ação clínica e prática psicológica na perspectiva fenomenológica existencial. No entanto, um dado chamou a atenção: o Aconselhamento Psicológico, a Psicoterapia Daseinsanalítica, o Psicodrama e a Oficina Sociopsicodramática são modalidades de prática psicológica que se apresentaram vinculadas à fenomenologia, o que parece indicar para um momento de transição ou questionamento dos pressupostos teórico-metodológicos que nortearam, inicialmente, a proposta de tais abordagens psicológicas. Também fica evidente que as modalidades de prática indicadas como Plantão Psicológico, a Supervisão de Apoio, a Oficina de Criatividade e o Psicodiagnóstico Interventivo/Colaborativo se apresentam vinculadas à perspectiva fenomenológica existencial. 


\section{Apresentando um Modo de Análise Compreensiva Hermenêutica}

Destacamos que os resultados da pesquisa-guia se mostraram como possibilidade para que, como pesquisadoras, ousássemos propor realizar uma análise compreensiva das produções referendadas pelo "estado da arte". Assim, remetemo-nos à hermenêutica filosófica de Gadamer como método e ao pensamento de Heidegger como interlocutor para pensar a prática psicológica.

Nessa direção, escolhemos trabalhar com a hermenêutica filosófica de Gadamer $(2008 ; 2010)$ que, tal como Heidegger, atribui à compreensão uma dimensão originária, mas seu interesse, diferente de Heidegger, volta-se para o movimento da compreensão e para a situação hermenêutica em sua especificidade. Assim, para Gadamer, toda compreensão envolve um componente histórico e se constrói na base de uma fusão de horizontes que abre caminho para a descrição do jogo da compreensão como jogo circular - círculo hermenêutico. A situação hermenêutica revela a presença de um horizonte compreensivo que é introduzido pela coisa a ser compreendida (determinações prévias) e o horizonte próprio de quem procura compreender (pressupostos), não conduzindo à retenção de cada um em sua identidade própria, mas privilegiando o acontecimento da compreensão. Assim, compreender é corrigir, incessantemente, as projeções originárias de sentido e significação, checando-as no interior do próprio exercício compreensivo. O processo de correção sempre acontece como fusão de horizontes - dois horizontes experimentam uma integração mútua no encontro no qual acontece a compreensão. Em tal condição, há uma interpenetração dos dois horizontes no jogo compreensivo que obedece às condições particulares de cada horizonte, gerando um movimento em que não há possibilidade de se pensar uma compreensão final como verdade metafísica.

Feitas tais observações, passamos a considerar a discussão dos resultados da pesquisa-guia como horizonte histórico da situação de produção de pesquisa nos Programas de Pós-Graduação com relação à ação clínica/prática psicológica na perspectiva fenomenológica existencial. Como pesquisadoras, procuramos compreender tal horizonte histórico partindo de nossos pressupostos para a realização da compreensão que só é levada a termo mediante o retorno crítico constante sobre esses pressupostos, permitindo que nasçam novas possibilidades compreensivas que revelam facetas diversas dos fenômenos a serem interpretados, na busca de um outro modo de ser do mesmo e do outro - possibilitando que dois horizontes fundam-se dialogicamente. 
Voltando ao diálogo com Martin Heidegger, ressaltamos que vamos apresentar um breve percurso sobre o seu pensamento, destacando algumas dimensões de sua obra que nos permitem ajudar a pensar o que se apresenta nas pesquisas estudadas sobre a ação clínica/prática psicológica numa perspectiva fenomenológica existencial.

Para tanto, consideramos a obra "Ser e tempo" de 1927 quando apresenta sua ontologia fundamental, a desconstrução da metafísica e o questionamento sobre o Sentido do Ser. Aqui reside um modo de pensar totalmente outro, pois, ao inverso da filosofia ocidental que sempre pensou o Ser apenas em relação aos entes, Heidegger propõe pensar o Ser enquanto tal; ou seja, o Ser sempre foi pensado a partir das coisas que são - o ser dos entes -, e não da sua originalidade de mostrar-se a partir do ser-aí (Dasein). Desse modo, como ser-aí, o homem é originalmente ex-sistência. Para Heidegger (2002), o ser-no-mundo é a estrutura fundamental ontológica do Dasein (ser-aí, existir); é o modo de ser (poder-ser) do Dasein. Perguntar, portanto, pelo modo de ser do homem, implica dizer que a essência do homem consiste na sua ex-sistencialidade, revelando-se como possibilidade: compreensão do Ser.

Nas obras tardias, escritas após a década de 30, ressaltamos seu pensamento sobre a essência da técnica e o modo como foi apresentada e delineada na modernidade pelo pensamento metafísico. Neste modo de pensar, a técnica é vista como instrumento, ferramenta. Entretanto, retomando o sentido originário, Heidegger (2012, p.139, grifos do autor) afirma:

Tékhné não significa, para os gregos, nem arte, nem artesanato, mas um deixar-aparecer algo como isso ou aquilo, dessa ou daquela maneira, no âmbito do que já estar em vigor. Os gregos pensam a tékhné [...], o produzir, a partir do deixar-aparecer.

Nesse sentido, é possível olhar o produzir como pôr em manifesto e é nesse intuito que nos propomos a apresentar uma análise compreensiva recorrendo a Heidegger (1959) quando, por meio de uma atitude de provoc(a)ção, no sentido de nos chamar à uma ação, convida-nos a uma atitude de Serenidade (1959), atitude esta que simultaneamente diz sim à inevitável utilização da técnica e, portanto, acolhe o modo calculante de pensar e, por outro lado, diz não ao acelerado uso da técnica moderna por meio de um olhar compreensivo que destaca uma dimensão meditativa e reflexiva do pensamento. 
Aqui, cabe explicitar que, para Heidegger (2002), a compreensão é vista como um existencial, sendo constitutiva do humano, distanciando-se, portanto, de uma noção de entendimento a qual tem uma função cognitiva cujas certezas podem transformar-se em "categorias". A compreensão, assim, é tomada como abertura, o modo como o sentido se desvela, podendo velar e revelar, dar a ver e encobrir-se, constituindo-se em diálogo. Desse modo, nesta análise compreensiva, narraremos o sentido que pode vir à luz, que se põe em manifesto a partir do diálogo realizado com o texto da discussão dos resultados encontrados na pesquisa-guia; portanto, afastamo-nos de uma verdade tida como certeza, uma vez que, para Heidegger (2002), toda compreensão está em sintonia com a disposição afetiva (abertura para o que pode vir à luz). Segundo Rodrigues (2006, p.59),

No discurso é que o homem se mostra como o ente que é; no entanto, está sempre implícita, na própria fala, a possibilidade de ocultamento do que de fato está em questão. A hermenêutica é que possibilita esse exercício de desvelamento, não de explicação, mas de compreensão e interpretação.

De acordo com Heidegger (2011, p.95, aspas do autor), “[...] o termo 'hermenêutico' não indicava como é costume a metodologia da interpretação, mas a própria interpretação". Tomando a mitologia, ele faz referência a Hermes, como o mensageiro dos deuses, dando notícia "à medida que consegue escutar uma mensagem" (p.96). Na análise compreensiva/interpretativa, lançaremos mão da "Hermenêutica" como a ação de trazer à luz o sentido e transmiti-lo. Colocando-nos como mensageiras, não dá para ter uma interpretação que não seja própria. Entretanto, sabemos que a interpretação se apresenta como mensageira da comunicação, como a possibilidade de dar sentido. Além de Heidegger (1959; 2002; 2006; 2011; 2012), para construirmos essa análise compreensiva, dialogaremos, ainda: com Walter Benjamin (1994), quando se refere à narrativa como um modo próprio do narrador tatuar a sua marca numa comunicação artesanal; com Hans-Georg Gadamer (2010), quando enfatiza a importância da fusão de horizontes em uma pesquisa, uma vez que o pesquisador, numa conversação com os pesquisados, ou como aqui, com o texto resultante dos resultados analisados, entrecruza histórias e cria outro sentido; com Michel Serres (1993), quando fala de um aprender mestiço, híbrido, próprio de um viajante que navega por caminhos desconhecidos e se lança no mistério do desbravar paisagens, conhecimentos, compreensões. 
Tendo esses autores como interlocutores, é possível tomar um levantamento realizado numa pesquisa do "estado da arte" e entrelaçar as informações colhidas com a nossa compreensão, apresentando não apenas informações ou discussões qualitativas sobre a temática investigada, mas, em especial, uma Análise Compreensiva/Hermenêutica de como o "estado da arte" chegou até nós e o possível sentido que podemos construir à medida que nos abrimos para experienciar um diálogo com o mesmo. Assim, recorremos a Heidegger (2006), numa tentativa de meditar sobre o fenômeno a ser compreendido, iniciando uma conversação com o texto da discussão dos resultados da pesquisa-guia e, tatuadas hibridamente pela experiência, criar uma narrativa que revele outra possibilidade compreensiva.

Vale ressaltar que esse modo de pensar reflexivo, lança um convite para ampliar nosso horizonte e olhar um fenômeno de vários lugares, inclusive com a possibilidade de conhecer pelo inverso, ou seja, "partindo daquilo que se mostra, vê-lo no seu avesso" (SANTOS, 2005, p. 314).

Seguindo em tal direção, estamos nos remetendo à questão do "pensar e do poetar" da linguagem, apontados por Heidegger, compreendidos como ação e não como resultado, sendo a linguagem uma possibilidade de desvelamento e não uma representação (GIACOIA Jr, 2013). Nesse sentido, apontamos que a "verdade" neste trabalho não está sendo vista como veritas, a qual busca confirmação, resposta, generalização, ou nas palavras de Duarte (2010, p.127, grifo do autor), "[...] concepção da verdade como adequatio, isto é, a verdade entendida como conformidade ou exatidão da representação em relação à coisa representada". Verdade é aqui tomada como aletheia, ou seja, como desocultamento, não velamento, como o modo pelo qual as informações colhidas se mostram para nós, enquanto pesquisadoras; falamos, então, de "verdades" flexíveis, mutantes, que colocam cada perquisador-viajante a caminho, numa atitude que requer tolerância às incertezas e abertura para criação de sentido. Por este olhar, "[...] mais do que o conteúdo, o lócus de desocultação, norteado pela aletheia, visa ao exercício da poiésis (linguagem) - aqui compreendida enquanto modo para comunicar sentido e não conteúdo.” (SANTOS, 2005, p.288).

Desse modo, tecemos uma "rede de vários fios que se cruzam, se rompem, se unem, se questionam dependendo do ponto que se estabelece como partida em cada texto" (FERREIRA, 2002, p.270). Compreendemos que tecer o "estado da arte" como uma rede implica um traçado de linhas que desenhem cruzamentos significativos, ou até mesmo choques e distanciamentos relevantes. Como sugerido por Guimarães Rosa (1985, p.14), uma rede pode ser vista como "Uma 
porção de buracos, amarrados com barbante...". Seguindo tal direção, gostaríamos que a compreensão tecida dos resultados da pesquisa-guia surgisse como uma rede que revela uma paisagem desenhada por entre buracos e barbantes sob a forma de uma narrativa resultante da fusão de horizontes, fruto da conversação estabelecida entre as pesquisadoras e os resultados encontrados (GADAMER, 2010). Explicitando melhor, recorremos a pensamento de Gadamer (2010, p.405), principalmente quando aponta que "Os horizontes separados como pontos de vista diferentes fundem-se num"; assim, nesta análise compreensiva pela via da conversação, compreendemos que é possível um encontro entrelaçado entre a discussão qualitativa dos resultados e a compreensão das autoras.

\section{Tecendo uma Análise Compreensiva da Rede de Informações Colhidas}

Após situarmos os autores com quem dialogamos, vamos procurar tecer uma rede de compreensão interligando as informações colhidas, numa conversação com a discussão qualitativa da pesquisa-guia, desenvolvendo uma compreensão hermenêutica dos resultados da pesquisa-guia, na tentativa de responder à questão: o que nos sugerem os resultados apontados pela discussão qualitativa da pesquisa-guia, se estivermos dispostos a refletir/meditar sobre as informações colhidas?

Para começarmos o jogo compreensivo, que nos guiará até esta questão, formulamos outra pergunta: como acontece a fusão do horizonte histórico da discussão qualitativa dos resultados da pesquisa-guia com o horizonte histórico compreensivo (pressupostos) das pesquisadoras?

Podemos dizer que a escolha por esta pesquisa já aponta que tanto a questão acima nos inquieta e mobiliza, como a discussão qualitativa nos forneceu informações que nos provocaram ir em direção a uma compreensão. Desse modo, ambas passam a ser nossas, e esta movimentação para uma compreensão é o que nos guia para tecer um diálogo com o texto apresentado pela discussão qualitativa dos resultados - uma conversação. Em tal atitude, é importante ressaltar a compreensão heideggeriana da "disposição afetiva", que nos ajuda a esclarecer não haver neutralidade nesse modo de pesquisar. Para Heidegger (2002, p.188, grifos do autor), "O que indicamos ontologicamente com o termo disposição é, onticamente, o mais conhecido e o mais cotidiano, a saber, o humor, o estado de humor". Assim, o modo de "ser afetado" pelo texto se afina 
com a pré-compreensão das pesquisadoras e abre-se como possibilidade para outra compreensão com o acontecer da fusão de horizontes.

Imersas em tal movimento, recorremos a uma das contribuições do pensamento de Heidegger (1959), quando ressalta a necessidade de refletir sobre o que buscamos compreender, assumindo uma atitude que espera para que o fenômeno se revele, numa disposição para aguardar que algo se desvele no horizonte compreensivo das pesquisadoras diante do texto resultante da discussão dos resultados. Tal atitude permite o acontecer da fusão de horizontes, condição pela qual dois horizontes, ao dialogarem, possibilitam a produção de outra possibilidade compreensiva.

Após essa breve apresentação sobre o modo como vamos caminhar, retomamos a discussão com os resultados da pesquisa-guia e deparamo-nos com o estranhamento diante da falta de distinção entre ação clínica e prática psicológica, bem como a falta de diferenciação entre as diversas abordagens fenomenológicas. Diante dessa realidade, refletimos: estaria nesta ausência de explicitação apenas a identificação/verificação de que em muitos trabalhos registrados na Plataforma da CAPES e da BDTB não há uma diferenciação entre esses termos?

Neste momento, vemo-nos perante o inesperado. Ao refletirmos sobre a situação encontrada, somos levadas a pôr em xeque nossos pressupostos para podermos acolher o novo que se mostra no texto e nos perguntamos: como os psicólogos pesquisadores transitam por essas indefinições e como compreendem o lugar que ocupam quando indicam que trabalham numa perspectiva fenomenológica existencial? Aqui nos reportamos a Wertz (2012, p. 359) quando, ao debater sobre as "correntes fenomenológicas na psicologia do século XX", ressalta a ambiguidade em relação à identidade da Psicologia, apontando a ausência de uma "univocalidade" da referida disciplina. Estaria nessa ambiguidade uma influência para o acontecer dessa indiferenciação? Ao mesmo tempo, não seria essa imprecisão uma abertura para acolher as diversas perspectivas fenomenológicas? Assim, o inusitado desta indiferenciação aponta considerar a necessidade de apropriação dos diversos olhares possíveis, próprios às diversas fenomenologias, e a busca de clareza com relação a um diálogo possível com cada filósofo, em especial com Heidegger, para pensar a ação clínica e a prática psicológica, ressaltando "elementos" de seu pensamento que ajudem a pensar a prática a partir da própria prática. Nessa direção, perguntamo-nos: construir uma narrativa sobre este lugar - o diálogo estabelecido - poderia ajudar em tal tarefa? Diante de tal questionamento, recorremos a Benjamin (1994, p. 205, aspas do autor), ao considerar a narrativa como 
[...] uma forma artesanal de comunicação. Ela não está interessada em transmitir o 'puro em-si' da coisa narrada como uma informação ou um relatório. Ela mergulha a coisa na vida do narrador para em seguida retirá-la dele. Assim se imprime na narrativa a marca do narrador, como a mão do oleiro na argila do vaso.

Assim, uma compreensão sobre o modo como exercemos uma prática como psicólogo e como pesquisador em diálogo com o pensamento de Heidegger poderia ser revelada pela via da narrativa, pois nela podem se mostrar as marcas de cada horizonte histórico compreensivo, bem como se defrontar com o modo como cada um se reconhece neste lugar e, entremeando as experiências com o processo de construção de conhecimentos sobre ação clínica e prática psicológica nessa perspectiva, desvelar um modo próprio de assumir o lugar constituído por essas marcas.

Ao falar de marcas, importa reconhecer a "marca" da fenomenologia husserliana em muitos dos trabalhos pesquisados. Vemos o valor de reconhecermos a importância de Husserl no surgimento da fenomenologia, mas fica evidente a necessidade de conhecermos os distintos olhares fenomenológicos com seus aportes epistemológicos e metodológicos diversos. Apesar de reconhecer a importância dos diversos olhares, chama-nos a atenção a consideração de Wartz (2012) quando aponta o distanciamento do diálogo entre a Psicologia e a Filosofia, principalmente na Psicologia americana. Diante de tal possibilidade, perguntamo-nos: estaria na inatividade desse diálogo uma falta de compreensão da heterogeneidade das perspectivas fenomenológicas?

Importa ressaltar que, partindo da fenomenologia de Husserl, Heidegger afasta-se da compreensão da intencionalidade da consciência e passa a assumir uma perceptiva mais hermenêutica, fundada na ontologia fundamental.

Apesar de tal distinção apresentar-se de modo claro nos escritos de Heidegger, percebemos que os pesquisadores dos trabalhos analisados parecem ter dificuldade em demarcar a diferença entre as diversas fenomenologias e apontar, com clareza, a perspectiva fenomenológica que orienta seu modo de trabalhar como psicólogo e como pesquisador. Seguindo na tentativa de compreender o horizonte histórico desvelado nos resultados encontrados, podemos dialogar com Serres (1993), e pensarmos a "marca" do pensamento de Husserl para 
os seguidores da perspectiva fenomenológica, considerando que, por sermos tatuados com-o-outro, colocamo-nos em um lugar mestiço. Tal pensamento poderia ajudar a compreender a dificuldade em romper com aquele que iniciou uma ruptura com o pensamento metafísico vigente no século XIX. Podemos ainda nos perguntar: tal dificuldade poderia apresentar-se como um movimento de atravessamento/passagem, uma abertura para a assunção do modo de ser psicólogo/pesquisador numa perspectiva fenomenológica existencial? Nessa direção, ainda refletirmos: será que a construção de uma narrativa, na qual se revelem as tatuagens impressas no caminhar de cada psicólogo/pesquisador, possibilitaria a apropriação da perspectiva fenomenologia assumida? Tal possibilidade compreensiva funda-se no diálogo com o pensamento de Benjamin (1994), no qual a narrativa se mostra como possibilidade de elaboração da experiência, que poderá revelar-se pela via das marcas decorrentes das tatuagens (SERRES, 1993), reconhecendo qual lugar habita, ou melhor, por qual modo cada psicólogo/pesquisador habita a fenomenologia.

É claro que tais possibilidades compreensivas não pretendem camuflar a falta de conhecimento sobre as diferentes perspectivas e sim ressaltar a dificuldade em romper com a "marca" inicial promovida por Husserl e que provocou toda uma reviravolta na Psicologia e nos modos de pesquisar os fenômenos humanos.

Voltando para os resultados da pesquisa-guia, deparamo-nos com a presença de apenas dois Laboratórios de Pesquisa que se apresentam como estando trabalhando na perspectiva fenomenológica existencial, ao modo de Heidegger, nas Regiões Nordeste e Sudeste do Brasil, e que aparecem, também, como os que mais desenvolveram pesquisas sobre ação clínica e prática psicológica na referida perspectiva. Tal contexto corrobora o que aponta Werts (2012, p.369) ao dizer que a fenomenologia existencial

[...] não está tipicamente representada em currículos acadêmicos, os alunos têm oportunidades limitadas de exposição. Os estudantes precisam descobrir a abordagem por conta própria ou por sugestão de um professor que, no máximo, ofereça oportunidades para o estudo independente.

Como um modo de trazer o texto da discussão dos resultados para o contexto das pesquisadoras, numa tentativa de entrarmos no mundo do texto para 
fazer sentido em nosso mundo, indagamos: haveria aqui uma sinalização de que é necessária a apresentação clara das diversas perspectivas do pensamento fenomenológico e de seus desdobramentos para a Psicologia, nos programas de Graduação e Pós-Graduação? Tal questionamento caminha na direção da reflexão do autor citado acima quando indica,

As tendências fenomenológicas ainda são uma perspectiva pequena e minoritária nesse tempo, em que a maioria dos pesquisadores continua a adotar uma abordagem hipotético-dedutiva científica natural que isola variáveis e apoia-se em medidas e em análise quantitativa. (WERTS, 2012, p.369).

Estaria aqui, mais uma vez, um modo possível de expressar a importância de cada pesquisador habitar o seu olhar fenomenológico? Compreendemos que essa realidade abre outros caminhos que poderiam apontar para a falta de reflexão sobre o enraizamento que provém do espírito da época que habitamos, dificultando que psicólogos/pesquisadores assumam uma visão epistemológica e metodológica que não confirme a tendência hegemônica da pesquisa em Psicologia, mesmo quando nos referimos à pesquisa qualitativa. Fazer pesquisa num viés fenomenológico e, mais especificamente, fenomenológico existencial, exige uma mudança de lugar, muitas vezes nos colocando à margem da produção reconhecida academicamente como válida cientificamente.

Agora, nossa atenção se volta para as modalidades de prática psicológica que se apresentaram vinculadas à perspectiva fenomenológica existencial, ao modo de Heidegger. Somos, mais uma vez, surpreendidas com a diversidade de modalidades e, deixando-nos "perturbar" pela novidade que o texto revela. Diante de tal estranhamento, remetemo-nos a Serres (1993), quando se refere ao modo como somos tatuados por nossas experiências e, habitando no estranhamento, perguntamo-nos: poderiam as tatuagens representadas pelos modos tradicionais de exercer a prática e a pesquisa psicológica se apresentarem como obstáculos para que os psicólogos/pesquisadores consigam apropriar-se e habitar um olhar fenomenológico, assumindo outras possibilidades de prática e outros modos de fazer pesquisa? Nesse sentido, surge um desafio para os psicólogos/pesquisadores das fenomenologias: dar a aparência de suas "peles" epistemológica e metodológica, mesmo que tatuada com as cores com que foi sendo revestida durante sua formação acadêmica. Mas... muitas vezes, é assustador 
mudar de direção, assumir uma outra tatuagem, quando nos vemos sozinhos e, reconhecemos o "desvanecimento das referências". Aqui lembramos de Benjamin (1994), quando nos provoca a lançarmo-nos como viajantes, a pormo-nos em trânsito, nutrindo outros pertencimentos e, como artesãs, imprimirmos nossa marca de modo singular. Nesta direção podemos dizer que a dispersão a partir da qual as perspectivas fenomenológicas se apresentaram se mostra como uma dificuldade do psicólogo/pesquisador poder marcar o seu lugar, ou seja, o lugar de onde está falando ao referir-se às fenomenologias.

Tal compreensão evidencia a importância de uma explicitação epistemológica e metodológica para os psicólogos/pesquisadores que trabalham com as fenomenologias. Leia-se, então, que esta é apenas uma possibilidade de se tecer essa rede, de construir sentido para a teia que se apresenta nos dados recolhidos pela pesquisa-guia. Contudo, dizemos do nosso desejo de deixar-nos levar adiante, colhendo outras informações, criando outro sentido, acompanhando-nos por entre articulações compreensivas, as quais nos colocam no trânsito de ser-na-leitura, artesãs/guardiãs/pastoras de um dizer-sentido, sobre a rede que tecemos - ou sobre a rede que se fez apresentar ante nosso próprio olhar.

\section{Uma Conversação na Tessitura do Sentido Desvelado}

Diante do cenário apresentado, continuaremos a tecer a rede de compreensão a fim de compormos a paisagem do sentido revelada pela análise compreensiva dos resultados colhidos na pesquisa-guia. Ao indicar um caminho, apontou para a necessidade de conhecer e desenvolver pesquisas sobre ação clínica/prática psicológica numa perspectiva fenomenológica existencial, dimensão que se configura um tema ainda pouco debatido academicamente.

Mas, caminhando com a visão de Guimarães Rosa (1985, p.14), de que uma rede se mostra como "Uma porção de buracos, amarrados com barbante...", podemos compreender que a escassez de trabalhos, como os buracos que compõem uma rede, não são retratos de um vazio, mas se mostram como abertura para continuarmos a fiar os barbantes já tecidos pelos pesquisadores dos 36 estudos realizados.

Iniciamos pelos barbantes, que nos apontaram para uma indiferenciação, presente no banco de dados da CAPES e da BDTD, com relação à prática psicológica e à ação clínica, bem como entre a fenomenologia e a fenomenologia 
existencial. Importa também ressaltar que a falta de explicitação da perspectiva fenomenológica em alguns trabalhos pesquisados provocou a exclusão de 14 pesquisas, já que o objetivo era investigar a ação clínica numa perspectiva fenomenológica existencial, ao modo de Heidegger. Surge, assim, o primeiro buraco dessa rede: é preciso explicitar qual a perspectiva fenomenológica que orienta a ação clínica e a pesquisa realizada pelos psicólogos.

Puxamos outros barbantes agora reveladores de como as Instituições de Ensino Superior (IES) no Nordeste e Sudeste do Brasil vêm desenvolvendo pesquisas sobre a ação clínica/prática psicológica na perspectiva fenomenológica existencial. Entrelaçando barbantes, vamos descobrindo que a UNICAP e a USP se destacam em produção de pesquisa de Pós-Graduação sobre a temática em foco, e ambas têm laboratórios que enfocam a Psicologia numa perspectiva fenomenológica existencial. O buraco que pudemos vislumbrar na rede foi a ausência de um laboratório específico, nas outras Instituições de Ensino Superior, para discutir pesquisas em tal perspectiva - importa demarcar nas IES um espaço que permita discutir a ação clínica/prática psicológica a partir do diálogo com o pensamento de Heidegger ou com outros fenomenológos, além de uma abertura para acolher pesquisas realizadas no viés fenomenológico.

Aproximando outros barbantes, eles nos fizeram olhar para as modalidades de prática psicológica presentes nos trabalhos pesquisados. Chama-nos a atenção a diversidade de modalidades, bem como suas intersecções com variadas abordagens da Psicologia. Revisitamos o primeiro buraco fotografado e deparamo-nos com o realce que apresenta para a importância de delimitação da perspectiva fenomenológica, possibilitando pensar uma determinada modalidade de prática psicológica. Mas, olhando para este buraco que se apresenta, outra questão surge: como compreender que uma modalidade de prática psicológica pode se apresentar, predominantemente, vinculada à perspectiva fenomenológica existencial? No caso, como compreender que o Plantão Psicológico, o Psicodiagnostico Interventivo/Colaborativo e as Oficinas de Criatividade apresentam-se como modalidades de prática psicológica predominante construídas em diálogo com o pensamento de Heidegger?

Sem a pretensão de responder objetivamente à questão em aberto, continuamos a olhar a rede tecida com seus barbantes e buracos e podemos considerar que tal possibilidade compreensiva permitiu ir além da discussão dos resultados da pesquisa-guia, cujo objetivo era fazer um levantamento sobre os trabalhos científicos (dissertações e teses) que pesquisaram a ação clínica/prática psicológica na perspectiva fenomenológica existencial. Ao assumir a hermenêutica 
Prof ${ }^{-a}$ Dr ${ }^{\text {a }}$ Henriette Tognetti Penha Morato [USP]

filosófica de Gadamer e realizar uma análise compreensiva dos resultados encontrados, foi possível, em diálogo com o pensamento de Heidegger, Serres e Benjamin, caminhar pelo inverso, no sentido de não apenas realizar uma discussão do que era visível no mapeamento bibliográfico, mas, olhando o seu avesso, questioná-lo.

Assim, surgiu a possibilidade de, indo além das informações e das explicações, compreender que a emergência de estudos no campo da ação clínica de psicólogos na perspectiva fenomenológica existencial, se revela quando ousamos assumir um diálogo entre a prática psicológica e o pensamento de Heidegger. Urge aos pesquisadores uma apropriação desse diálogo, como também das ressonâncias que se apresentam na compreensão da ação clínica que atravessa a prática do psicólogo. Desse modo, por entre barbantes e buracos, fiamos uma possível compreensão sobre o cenário que se apresenta na produção científico-acadêmica sobre a ação clínica numa perspectiva fenomenológica existencial.

BARRETO, C. L. B. T. 2006. Ação clínica e os pressupostos fenomenológicos existenciais. São Paulo. $215 \mathrm{f}$. Tese (doutorado). Universidade de São Paulo, 2006.

\section{Reflexões para pensar a ação clínica a partir} do pensamento de Heidegger: da ontologia fundamental à questão da técnica. In: BARRETO, C. L. B. T., MORATO, H. T. P.; CALDAS, M. T. (orgs). Prática psicológica na perspectiva fenomenológica. (pp. 2750). Curitiba: Juruá, 2013.

BENJAMIN, W. O narrador: considerações sobre a obra de Nikolai Leskov. In: Magia e técnica, arte e política. (pp.197-221). 7.ed. São Paulo: Brasiliense, 1994.

CABRAL, B. E; MORATO, H. T. P. A questão de pesquisa como bússola: notas sobre o processo de produção de conhecimento em uma perspectiva fenomenológica existencial. In: BARRETO, C. L. B. T., MORATO, H. T. P.; CALDAS, M. T. (orgs) Prática psicológica na perspectiva fenomenológica. (pp. 159-181). Curitiba: Juruá, 2013.

CRITELLI, D. M. Analitica do sentido: uma aproximação e interpretação do real de orientação fenomenológica. São Paulo: EDUC/Brasiliense, 1996.

DUARTE, A. Vidas em risco: crítica do pensamento em Heidegger, Arendt e Foucault. Rio de Janeiro: Forense Universitária, 2010.

FEIJOO, A. M. L. C. de. A psicoterapia em uma perspectiva fenomenológico-existencial. In: ANGERAMINI-CAMON, V. A. (org.). Psicoterapia fenomenológico-existencial. (p.p. 131-158). São Paulo: Pioneira Thomson Learning, 2002.

FERREIRA, N. S. de A. As pesquisas denominadas "estado da arte”. In: Revista Educação \& Sociedade. Campinas, Ano XXIII, nº 79, p. 257-272, 2002. UNICAMP 
(Universidade de Campinas). $<$ http://www.fe.unicamp. br/alle/textos/NSAF-AsPesquisasDenominadasEstadodaArte.pdf $>$. Disponibilidade: acesso em 27 de novembro de 2012.

FORGHIERI, Y. C. Psicologia fenomenológica: fundamentos, método e pesquisas. São Paulo: Pioneira Thomson Learning, 2002.

GADAMER, H. Verdade e método I: traços fundamentais de uma hermenêutica filosófica. 10.ed. Petrópolis/ RJ: Vozes, 2008.

. Verdade e método II: complementos e índice.

5.ed. Petrópolis/RJ: Vozes, Bragança Paulista: Editora Universitária São Francisco, 2010.

GIACOIA Jr., O. Heidegger urgente: introdução a um novo pensar. São Paulo: Três Estrelas, 2013.

GIORGI, A.; Sousa, D. Método Fenomenológico de Investigação em Psicologia. Lisboa: Fim de Século, 2010.

HEIDEGGER, M. A caminho da linguagem. 5.ed. Petrópolis/RJ: Vozes; Bragança Paulista /SP; Editora Universitária São Francisco, 2011.

Ensaios e conferências. 8.ed. Petrópolis/RJ: Vozes; Bragança Paulista/SP; Editora Universitária São Francisco, 2012.

.Seminários de Zolikon. Petrópolis/RJ: Vozes, 2006.

. Serenidade. Lisboa: Instituto Piaget, 1959.

Ser e tempo. 12. ed. Petrópolis/RJ: Vozes, 2002.

MOREIRA, V. Clínica humanista-fenomenológica: estudos em psicoterapia e psicopatologia crítica. São Paulo: annablume, 2009.
RODRIGUES, J. T. Terror, medo, pânico: manifestações da angústia no contemporâneo. Rio de Janeiro: 7Letras, 2006.

ROSA, G. Tutaméia. 6. ed. Rio de Janeiro: Nova Fronteira, 1985.

SANTOS, S. E. de B. 2006. A experiência de ser ex-esposa: uma oficina sociopsicodramática como intervenção para problematizar a ação clínica. Recife. 344f. Dissertação (mestrado) Universidade Católica de Pernambuco, 2005.

SERRES, M. Filosofia mestiça: le tiers - instruit. Rio de Janeiro: Nova Fronteira, 1993.

SPOSITO, M. P. Estado da Arte sobre juventude: uma introdução. In: SPOSITO, M. P. (coord.). Estado da Arte sobre juventude na pós-graduação brasileira: educação, ciências sociais e serviço social (1999-2006). volume 1. Belo Horizonte/MG: Argvmentvm, 2009. p.11-15.

WERTZ, F. J. Correntes fenomenológicas na psicologia do século XX. In: DREYFUS, H. I; WRATHALL, M. A (orgs). Fenomenologia e existencialismo. São Paulo: Edições Loyola, 2012. p.359-373. 